\title{
A Comparative Study on the Performance of Fiber-Based Biosorbents in the Purification of Biodiesel Derived from Camelina sativa
}

\author{
Jie Yang ${ }^{1}$, Quan (Sophia) He ${ }^{1, *}$, Haibo Niu ${ }^{1}$, Kenneth Corscadden ${ }^{1}$ and Claude Caldwell ${ }^{2}$ \\ ${ }^{1}$ Department of Engineering, Faculty of Agriculture, Dalhousie University, Truro, NS B2N 5E3, Canada \\ ${ }^{2}$ Department of Plant and Animal Science, Faculty of Agriculture, Dalhousie University, Truro, NS B2N 5E3, \\ Canada
}

\begin{abstract}
Biodiesel has received great interest as a promising substitute for petrodiesel. Biodiesel purification which follows the transesterification process is typically carried out using a wet washing process that generates large amounts of wastewater. Consequently, alternative methods are emerging as sustainable options for biodiesel purification. One of such methods is a dry washing process. In this paper, the performance of three dry washing media (commercially available BD-Zorb, sawdust and wood shavings) were evaluated as potentially suitable options for the purification of biodiesel derived from Camelina sativa. The results indicate that for the crude camelina biodiesel with an initial soap content of $9007 \mathrm{ppm}$, BD-Zorb exhibited the best purification performance. The soap removal capacity of BD-Zorb, sawdust, and wood shavings was $51.1 \mathrm{~mL} / \mathrm{g}, 24.4 \mathrm{~mL} / \mathrm{g}$, and $9.4 \mathrm{~mL} / \mathrm{g}$ respectively. The primary mechanism of soap removal using sawdust and wood shavings media was physical filtration and adsorption. While for adsorbent BD-Zorb, soap removal mechanism included adsorption and ion exchange due to the existence of a small amount of resins. The ion exchange led to a high acid number $(1 \mathrm{mg} \mathrm{KOH} / \mathrm{g})$ of the purified biodiesel, and failed to meet the ASTM D6751 specifications (<0.5 mg KOH/g).
\end{abstract}

Keywords: Drying washing, purification of biodiesel, adsorbent, wood waste, Camelina sativa.

\section{INTRODUCTION}

The extensive use of fossil fuels has resulted in a dramatic decline in petroleum reserves, severe air pollution and growing concerns over global warming [1, 2] in recent years. These combined factors are driving researchers and industry practitioners to seek viable fuel alternatives. Biodiesel, a renewable, biodegradable and environmentally innocuous biofuel, has shown great potential to be used as a substitute for conventional petro-diesel [3-5].

Alkali-catalyzed transesterification is typically used for biodiesel production at an industrial scale due to fast reaction rate, mild reaction conditions, low cost of catalysts and easy operation. It is a process where vegetable oils (triglycerides) react with alcohol (usually methanol) to generate a mixture of fatty acid monoalkyl esters (FAME or biodiesel) and a by-product (glycerol) in the presence of alkaline catalysts ( $\mathrm{KOH}$ or $\mathrm{NaOH}$ ). The majority of glycerol can be removed from biodiesel by phase separation because of the density and polarity difference between them. However, after glycerol removal, crude biodiesel still contains a variety of impurities, such as alcohol, catalyst, water, unremoved trace amounts of glycerol, unreacted

*Address correspondence to this author at the Department of Engineering, Faculty of Agriculture, Dalhousie University, Truro, NS B2N 5E3, Canada; Tel: 902893 6180; Fax: 902 8901859; E-mail: Quan.He@Dal.Ca mono-, di- and tri-glycerides, free fatty acids and soap $[6,7]$. The presence of those impurities may lead to adverse effects on fuel quality and the diesel engine [8, 9]. For example, an excess amount of total glycerol in biodiesel will cause undesirable deposits which may clog fuel lines and pumps [10]. Naturally occurring free fatty acids in vegetable oil can react with the catalyst, $\mathrm{KOH}$ or $\mathrm{NaOH}$ to form soap through a saponification process, which takes place in parallel with transesterification. Similar to glycerol, a high soap content can result in engine wear and negatively impact engine lifespan [6, 11]. Although there is no explicit specification of soap content in ASTM D6751, the generally acceptable soap limit should be lower than $66 \mathrm{ppm}$ in the case where $\mathrm{KOH}$ is used as a catalyst in the biodiesel production processes. The existence of soap in biodiesel causes ash formation in diesel engine cylinders during biodiesel combustion. Water content $(\leq 500 \mathrm{ppm})$ in biodiesel is another critical parameter associated with biodiesel quality. A high water content reduces the energy efficiency of fuel combustion, enhances the hydrolysis of FAME and even forms ice crystals resulting in gelling of fuels [12]. The FFA percentage in biodiesel is closely related to its acid number $(\leq 0.5 \mathrm{mg} \mathrm{KOH} / \mathrm{g})$, which can cause corrosion of the engine's components [6]. Therefore, proper purification processes are essential to remove or minimize those impurities in crude biodiesel to meet standard specifications. 
A traditional approach for the purification of biodiesel at a commercial production scale is wet washing, based on the removal of water-soluble contaminants. Warm distilled or deionized water can effectively remove residual glycerol, soap, alcohol and catalyst from crude biodiesel. However, this process consumes a great amount of fresh water and generates aqueous effluent that has a detrimental impact on the environment [10]. Therefore, efforts have shifted to develop dry washing processes, using adsorbents such as resins [13], silicate magnesol [14], activated carbon $[15,16]$ and fiber-based materials [17, 18], or using membranes [19]. The adsorption capacity of cellulose fiber, a natural polymer derived from biomass has been demonstrated in a number of applications [20-25]. Recently, several economical alternatives such as Eucalyptus pulp [17] and Rice husk ash [18] have been used to adsorb impurities in crude biodiesel. BD-Zorb is a fiber-based commercially available dry wash medium for biodiesel purification. From its appearance, it consists mainly of wood chips and a small amount of resins. Due to commercial confidentiality, it is difficult to obtain any information on the species of wood chips, physical/chemical treatment of wood chips and chemical composition of the resins. This encourages us to explore the possibility of using sawdust and wood shavings, large amounts of waste generated by wood processing plants as biosorbents for biodiesel purification. Additionally, more than $95 \%$ of biodiesel worldwide is currently derived from traditionally edible vegetable oils such as soybean, canola and sunflower $[26,27]$; this competes with the food and feed supply, raising a heated debate on "fuel vs. food." Recent research has identified Camelina sativa, as a promising and sustainable oilseed crop for biodiesel production in North America [28, 29]. Camelina seed has a fairly high oil content $(35-43 \%$ on a dry matter basis) [30,31], has a short growing season and is tolerant to drought, cool weather and insect pests $[32,33]$.

In this study, using camelina biodiesel as a model crude biodiesel, we explored the potential of using wood wastes such as sawdust (SD) and wood shavings (WS) as biosorbents in the dry washing purification processes, and compared the performance of the wood waste to that of commercially available adsorbent, BD-Zorb. The soap level, acid number and water content of purified biodiesel were indicators for evaluating the purification performance of dry wash media.

\section{MATERIALS AND METHODS}

\subsection{Materials}

Unrefined camelina oil was cold pressed from seeds grown in Canning, Nova Scotia, Canada. Potassium hydroxide in the form of pellets, analytical grade methanol (>99\%), hexane and ethanol were purchased from Fisher Scientific Ltd., Canada. Xylene, chroloform and two titratants (composite 5 and $0.1 \mathrm{~N} \mathrm{KOH}$ ) were purchased from Sigma Aldrich. Canada. A standard reference solution of camelina methyl esters (GLC 937, $>99 \%$ ) was purchased from Nu-Chek Prep. Inc. USA. Three fiber-based adsorbents used in this study are shown in Figure 1. BD-Zorb was purchased from Utah Biodiesel Supply Ltd., USA, and sawdust and wood shavings were provided by the wood shop in Dalhousie University, Agricultural Campus, Truro, NS, Canada.

\subsection{Characterization of Adsorbents}

The surface morphology of three adsorbents was studied by scanning electron microscopy (SEM) in a Hitachi S-4700 equipment with $10 \mathrm{kV}$ and magnification

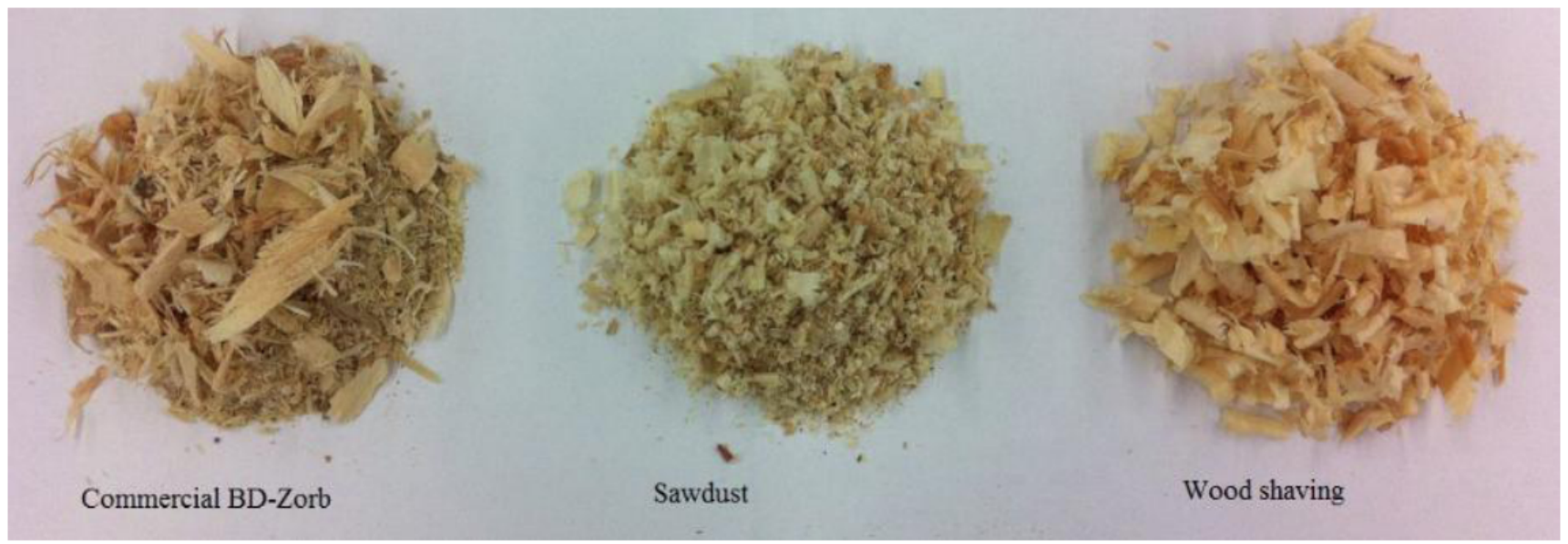

Figure 1: Three adsorbents applied for biodiesel purification: BD-Zorb, sawdust and wood shavings. 
of up to 5000x. The Brunauer-Emmett-Teller (BET) specific surface area of adsorbents were determined by the Quantachrome Autosorb-3B with Krypton as the adsorbate. The functional groups of sawdust were analyzed using Fourier Transform Infrared (FT-IR) Spectrometer (PerkinElmer Spectrum One) in the range of $4000-400 \mathrm{~cm}^{-1}$ with a resolution of $4 \mathrm{~cm}^{-1}$ and 32 scans.

\subsection{Camelina Biodiesel Synthesis}

Camelina biodiesel was prepared by an ultrasoundassisted transesterification process [34]. $1 \mathrm{~kg}$ camelina oil was added to the reactor, and the temperature was set at $50{ }^{\circ} \mathrm{C}$, a reaction time of 1 hour, methanol/oil molar ratio of $8: 1$ and $1.3 \mathrm{wt}$. $\% \mathrm{KOH}$ catalyst with respect to oil feed $[35,36]$. The reaction mixture was transferred to a separatory funnel and allowed to stand for $30 \mathrm{~min}$ for phase separation. The glycerol layer under the crude biodiesel was drawn off, giving $0.93 \mathrm{~kg}$ crude biodiesel layer for further purification.

\subsection{Purification Process}

The purification of crude camelina biodiesel in a dry washing process was performed in three cylindrical separator funnels $(125 \mathrm{~mL})$, each filled with $18 \mathrm{~g} \mathrm{BD}$ Zorb, sawdust and wood shavings respectively. Cotton gauze was applied on the top of the packed absorbent to distribute the added crude biodiesel evenly and minimize the channeling effect. Cotton gauze was also placed at the bottom of the adsorbent bed to hold the mass. The flow rate of biodiesel was $100 \mathrm{~mL} / \mathrm{h}$ and was controlled using a rotary knob and effluent was collected every $50 \mathrm{~mL}$ for further testing.

In a wet washing purification process, $50 \mathrm{~mL}$ of crude camelina biodiesel was transferred to a $250 \mathrm{~mL}$ separatory funnel and washed by adding $100 \mathrm{~mL}$ of distilled water until the water layer was transparent. The temperature of distilled water was set at $20^{\circ} \mathrm{C}$ and $50{ }^{\circ} \mathrm{C}$ to compare the effect of water temperature on purification efficiency. All purification operations were conducted in duplicate.

\subsection{Characterization of Camelina Biodiesel}

The content of fatty acid methyl esters (FAME) at camelina biodiesel were determined using an Agilent 7890A Gas Chromatography (GC) equipped with a flame ionization detector (FID) and an Agilent DB-23 column (50\%-Cyanopropyl-methylpolysiloxane; $30-\mathrm{m}$ length $\times 0.25-\mathrm{mm}$ internal diameter $\times 0.25 \mu \mathrm{m}$ thickness; high polarity). The fatty acid methyl esters were identified by comparing their specific retention times to those of a standard reference solution of camelina methyl esters (GLC 937).

The soap level of biodiesel was determined by titration examination: $12 \mathrm{~mL}$ biodiesel and $1 \mathrm{~mL} 0.04 \%$ aqueous Bromophenol blue were added into $100 \mathrm{~mL}$ of isopropanol. The solution was mixed well using magnetic stirring, followed by dropwise adding $0.01 \mathrm{~N}$ hydrochloric acid $(\mathrm{HCl})$ until the color of the solution changed from blue or/and green to yellow. The amount of $\mathrm{HCl}$ used $(\mathrm{mL})$ was recorded and the soap level of biodiesel was determined as follows:

Soap content $(\mathrm{ppm})=$ the amount of $\mathrm{HCl}$ added $(\mathrm{mL})$ * 320

Where 320 is the average molecular weight of soap in biodiesel.

The water content of biodiesel was determined by Karl Fisher volumetric testing method in Mettler Toledo T7 titrator. Biodiesel sample of $3 \mathrm{~g}$ was added into titration vessel containing $40 \mathrm{~mL}$ methanol and $30 \mathrm{~mL}$ chloroform and xylenes mixture (1:1 in volume), followed by adding titrant (composite 5 ) automatically until reaching the ending point. The water content was calculated shown in the panel of titrator. The acid number of camelina biodiesel was measured by an accessory electrode coupled in Mettler Toledo titrator. 15 grams of biodiesel was dissolved in $60 \mathrm{~mL}$ of diethyl and ethanol mixture (1:1 in volume) in titration vessel. $0.1 \mathrm{~N} \mathrm{KOH}$ titrant was stepwise purged into the titration vessel to determine the acid number.

\section{RESULTS AND DISCUSSION}

\subsection{Characterization of Adsorbents}

The macroporous structures of the three fiber-based biosorbents of interest in this study were captured using a SEM under two different magnifications (500x and 2000x) as shown in Figure 2. BD woodchips (Figure $\mathbf{2 a}$ and $\mathbf{2 b}$ ) have fewer pores compared to sawdust (Figure $\mathbf{2 c}$ and $\mathbf{2 d}$ ) and wood shavings (Figure $2 \mathbf{e}$ and $\mathbf{2 f}$ ). BET analysis indicated that SD had the largest specific surface area $\left(1.06 \mathrm{~m}^{2} / \mathrm{g}\right)$ of these three dry wash media, followed by WS $\left(0.8 \mathrm{~m}^{2} / \mathrm{g}\right)$ and $\mathrm{BD}$ $\left(0.49 \mathrm{~m}^{2} / \mathrm{g}\right)$ as shown in Table 1.

\subsection{Characterization of Crude Camelina Biodiesel}

The properties of crude biodiesel and the composition of fatty acid methyl esters were presented 


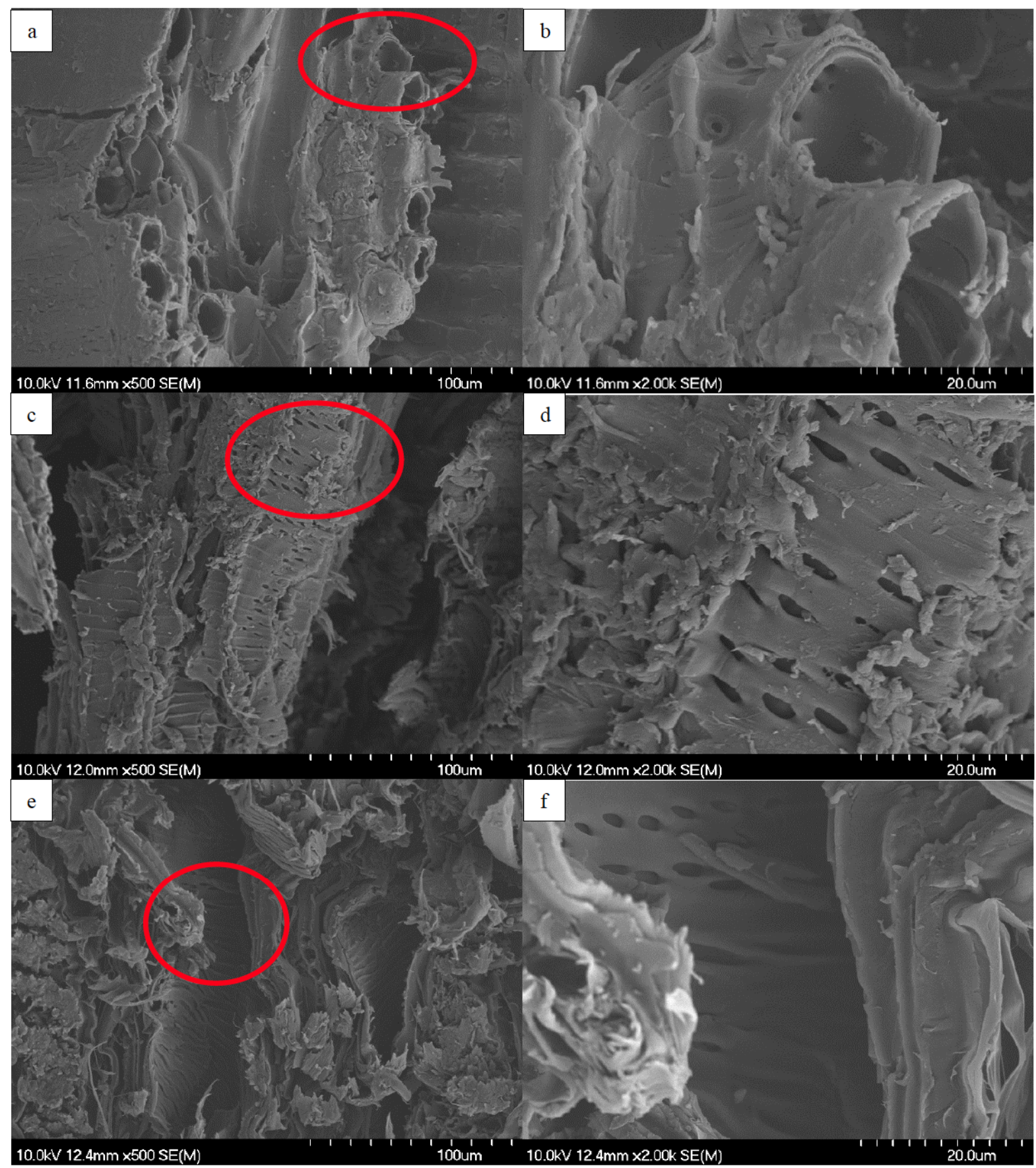

Figure 2: SEM images of BD woodchips (a \& b), sawdust (c \& d) and wood shaving (e \& f) under two different magnifications $(500 \times \& 2000 \times)$.

Table 1: Specific Surface Areas of Three Fiber-Based Biosorbents

\begin{tabular}{|c|c|c|c|}
\hline & BD-Zorb & Sawdust & Wood Shavings \\
\hline \hline Specific surface area, $\left(\mathrm{m}^{2} / \mathrm{g}\right)$ & 0.49 & 1.06 & 0.80 \\
\hline
\end{tabular}

in Table 2. Crude camelina biodiesel contained $97.5 \mathrm{wt}$. $\%$ of FAME, complying with EN14214 standard. The water content of crude camelina biodiesel of $2011 \mathrm{ppm}$ was much higher than the minimum values specified in biodiesel quality references, ASTM D6751 or EN 14214. The acid number was $0.07 \mathrm{mg} \mathrm{KOH} / \mathrm{g}$, a pretty 
Table 2: The Properties of Fatty Acid Profile of Crude Camelina Biodiesel

\begin{tabular}{|c|c|c|c|}
\hline Soap content (ppm) & - & - & 9007 \\
\hline Water content (ppm) & 500 & 500 & 2011 \\
\hline FAME (wt. \%) & - & 96.5 & 97.5 \\
\hline Palmitic methyl ester, C16:0 & & & 5.5 \\
\hline Palmitoleic methyl ester, C16:1 & & & 0.1 \\
\hline Stearic methyl ester, C18:0 & & & 2.4 \\
\hline Oleic methyl ester, C18:1 & & & 14.4 \\
\hline Gadoleic methyl ester, C20:1 & & & 15 \\
\hline Eicosadienoic methyl ester, C20:2 & & & 2.2 \\
\hline Arachidonic methyl ester, C20:4 & & & 1.4 \\
\hline Behenic methyl ester, C22:0 & & & 0.3 \\
\hline Erucic methyl ester, C22:1 & & & 3.1 \\
\hline Clupanodinic methyl ester, C22:2 & & & 0.2 \\
\hline Docosatrienoic methyl ester, C22:3 & & & 0.4 \\
\hline Lignoceric methyl ester, C24:0 & & & 0.2 \\
\hline
\end{tabular}

Note: the individual percentage of fatty acid methyl esters were adapted from our previous work [38].

low value against biodiesel specifications. The soap content in crude camelina biodiesel was $9007 \mathrm{ppm}$, relatively high compared to other studies $[13,37]$.

The high-level of soap resulted from a stoichiometric excess of $\mathrm{KOH}(1.3$ wt. \%), and thus saponification reaction between FFA in parent camelina oil and $\mathrm{KOH}$ occurred during the transesterification process. The reaction mechanism of saponification was shown in Figure 3. The hydrogen ions in FFA can be readily replaced by potassium ions $\left(\mathrm{K}^{+}\right)$from $\mathrm{KOH}$ and then form soap and water. It is worthwhile to point out that the soap level was high because the soap measurement was taken right after the glycerol removal in the present study. If the crude biodiesel after separating glycerol had settled for a period of time, the soap would partially concentrate at the bottom of the storage tank, and could then be separated by density difference, which would greatly reduce the burden for downstream purification. In this study, the crude camelina biodiesel with a soap level of $9007 \mathrm{ppm}$ was used for evaluating the performance of the three biosorbents in the following sections.

\subsection{Purification of Crude Biodiesel Using Different Fiber-based Dry Wash Media}

Crude camelina biodiesel with an initial soap level of $9007 \mathrm{ppm}$ was purified by using three fiber-based adsorbents, including commercially available BD Zorb
$\mathrm{O}$<smiles>C=C(C)O</smiles>

$\mathrm{KOH}$

$\longrightarrow$

\section{Fatty Acid Potassium Hydroxide}

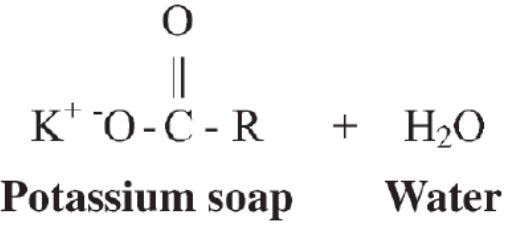

Figure 3: Formation of soap between fatty acid and excessive $\mathrm{KOH}$ catalyst [37]. 


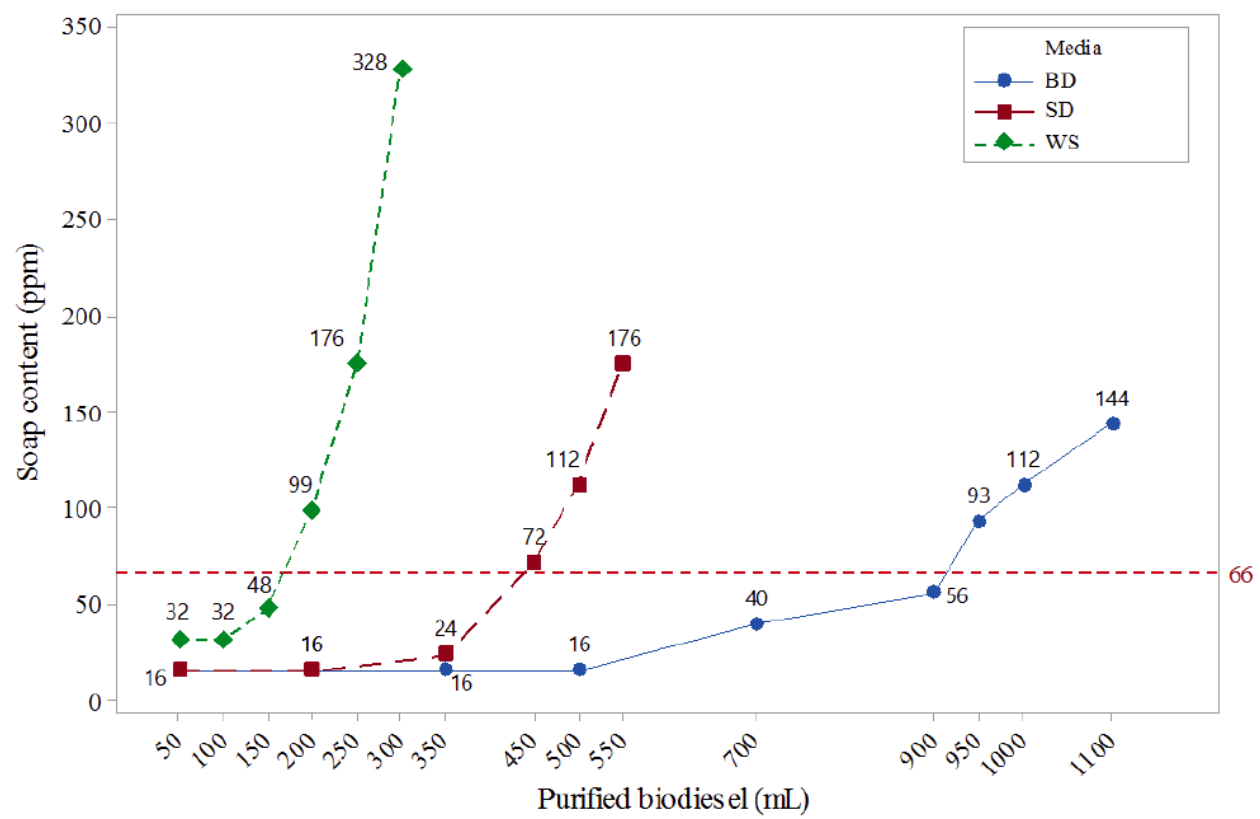

Figure 4: Comparison of soap removal efficiency of the three dry wash media, BD Zorb (BD), Sawdust (SD) and Wood shavings (WS) (18 g each).

and waste products from wood processing plants (sawdust and wood shavings). Figure 4 presents a comparison of the soap removal efficiency of these three adsorbents. Clearly, all of them were effective in removing soap and decreased the soap content from the initial concentration of $9007 \mathrm{ppm}$ to less than 66 ppm for the first $150 \mathrm{~mL}$ of biodiesel treated. However, wood shavings were saturated by soap quickly and their adsorption ability decreased. The soap level increased to $99 \mathrm{ppm}, 176 \mathrm{ppm}$ and $328 \mathrm{ppm}$ when treating $200 \mathrm{~mL}, 250 \mathrm{~mL}$ and $300 \mathrm{~mL}$ of biodiesel respectively. Sawdust displayed a better soap removal ability than wood shavings, and the soap level was 72 ppm after treating $450 \mathrm{~mL}$ crude biodiesel as shown by the red dashed line. This was mainly attributed to a larger specific surface area of SD than that of WS as shown in Table 1. Compared to WS and SD, BD Zorb exhibited much higher soap removal efficiency even though its specific surface area was lower than that of SD. The soap level of biodiesel purified using BD Zorb was $56 \mathrm{ppm}$ after treating $900 \mathrm{~mL}$ of crude biodiesel. This is because a small amount of resin exists in BD Zorb, which enabled soap removal more effectively than could be achieved using fibers [13].

The acid number of biodiesel is a good indicator of free fatty acid (FFA) content in biodiesel, representing its degree of acidity. In the transesterification process, excessive $\mathrm{KOH}$ was applied to obtain high quality biodiesel. Therefore, the initial acid number of crude camelina biodiesel was very low $(0.07 \mathrm{mg} \mathrm{KOH} / \mathrm{g})$. The effects of dry wash media on the acid number of the purified biodiesel are shown in Figure 5. The acid number of BD Zorb purified for the first $50 \mathrm{~mL}$ of biodiesel was $1.73 \mathrm{mg} \mathrm{KOH} / \mathrm{g}$, which was higher than the initial value of $0.07 \mathrm{mg} \mathrm{KOH} / \mathrm{g}$. This can be explained due to the small amount of resin existing in BD Zorb removing soap via ion exchange and thus generated a considerable amount of FFA, leading to an increased acid number. A steadily declining trend of acid number was observed as the volume of treated biodiesel increased, indicating that the ability of resins to remove soap decreased gradually when the crude camelina biodiesel was continuously fed to the BD Zorb bed. The acid number of purified biodiesel using sawdust and wood shavings also increased to $0.43 \mathrm{mg}$ $\mathrm{KOH} / \mathrm{g}$ and $0.38 \mathrm{mg} \mathrm{KOH} / \mathrm{g}$ respectively from the initial value of $0.07 \mathrm{mg} \mathrm{KOH} / \mathrm{g}$ when the first $50 \mathrm{~mL}$ crude biodiesel was treated, and then decreased with increasing amounts of crude biodiesel. The acid number of the biodiesel purified by sawdust and wood shavings were lower than $0.5 \mathrm{mg} \mathrm{KOH} / \mathrm{g}$, the limit specified in the ASTM standard, but BD Zorb purified biodiesel had a much higher acid number $(1.01 \mathrm{mg}$ $\mathrm{KOH} / \mathrm{g}$ ) and failed to meet biodiesel standards.

Figure 6 showed the water removal efficiency of the three dry wash media. It was found that the three media were able to adsorb water from the crude camelina biodiesel to a certain degree, however failed to meet the ASTM D6751 (<500ppm) requirement. The water content decreased from an initial level of 2011 


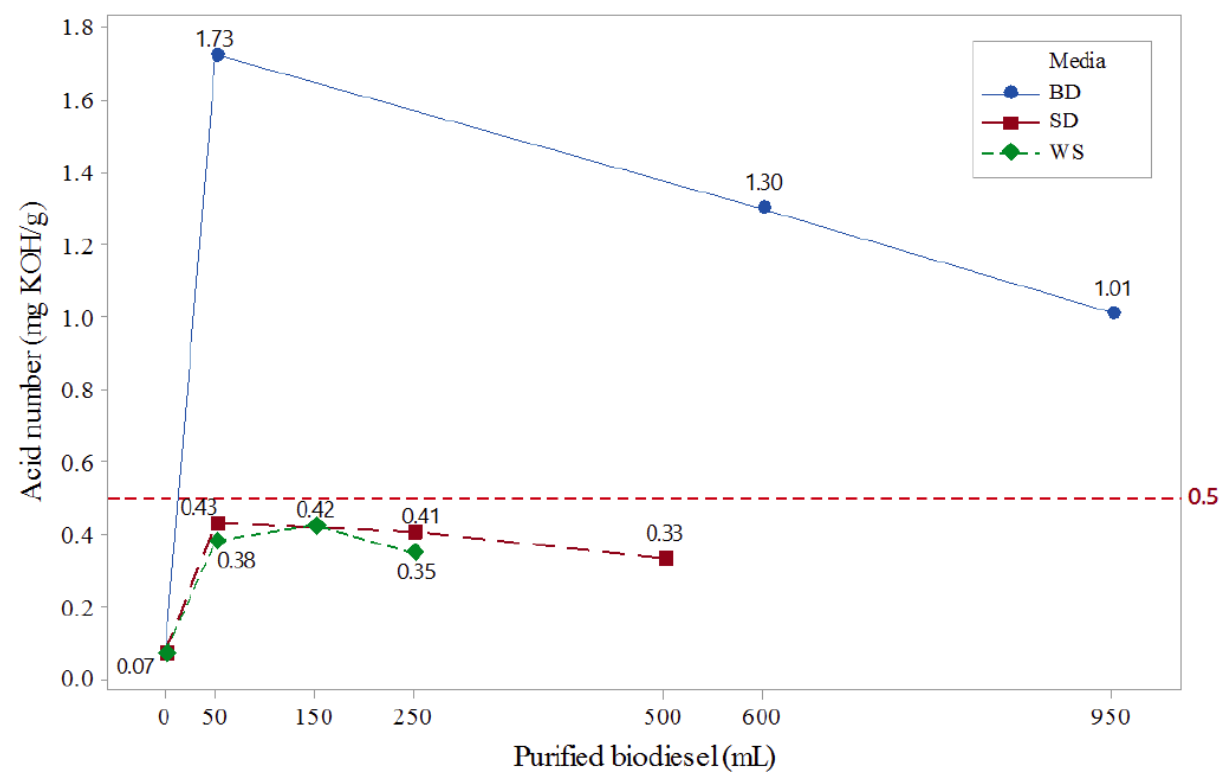

Figure 5: Acid number of the purified camelina biodiesel treated by dry washing media, BD Zorb (BD), Sawdust (SD) and Wood shavings (WS) respectively (18 g each).

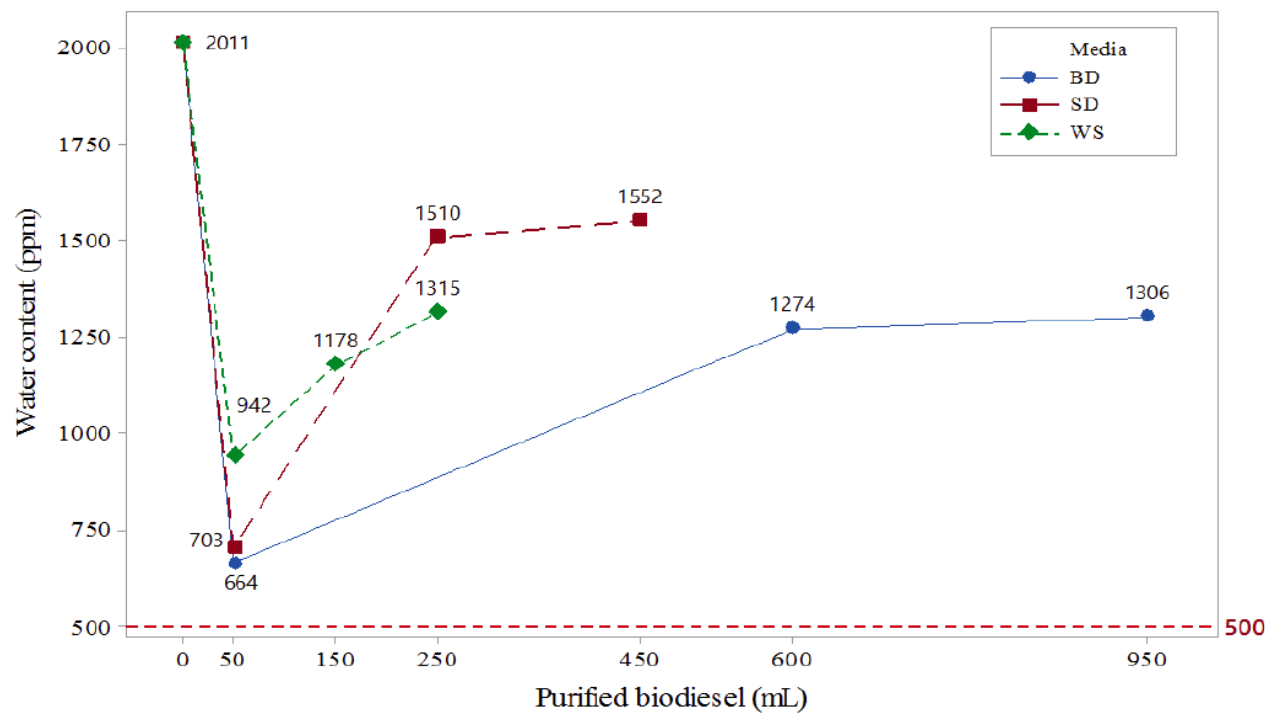

Figure 6: Comparison of the water content of the purified camelina biodiesel treated by dry washing media, BD Zorb (BD), Sawdust (SD) and Wood shavings (WS) (18 g each).

ppm to about $664-942 \mathrm{ppm}$ when the first $50 \mathrm{~mL}$ of biodiesel was purified, and then gradually increased with increasing amounts of crude biodiesel fed to purification columns. The water content in the purified biodiesel was associated with the dryness of the three adsorbents. As this study mainly focused on the soap removal ability of sawdust and wood shavings, the moisture content of three adsorbents was not tested and recorded.

In summary, the soap removal capacity of the three fiber-based biosorbents was $9.4 \mathrm{~mL} / \mathrm{g}, 24.4 \mathrm{~mL} / \mathrm{g}$ and $51.1 \mathrm{~mL} / \mathrm{g}$ for wood shavings, sawdust and commercially available BD-Zorb respectively (soap content threshold set at $66 \mathrm{ppm}$ ). Table 3 also showed the water content and acid number of purified camelina biodiesel.

Based on these observations, it was found that the purification mechanism of sawdust and wood shavings was mainly due to physical filtration and adsorption. Porous fiber-based materials were able to absorb soap and moisture. Sawdust has a larger specific surface area than wood shavings, therefore showed a higher purification capacity. lon exchange mechanisms may also be involved. Sawdust and wood shavings typically 
Table 3: The Properties of Camelina Biodiesel Purified by Dry Wash Media and their Adsorption Capacities

\begin{tabular}{|c|c|c|c|c|c|}
\hline $\begin{array}{c}\text { Adsorbent } \\
\text { Used }\end{array}$ & $\begin{array}{c}\text { Soap Content } \\
(\mathbf{p p m})\end{array}$ & $\begin{array}{c}\text { Acid Number } \\
(\mathbf{m g ~ K O H} / \mathbf{g})\end{array}$ & $\begin{array}{c}\text { Water Content } \\
(\mathbf{p p m})\end{array}$ & $\begin{array}{c}\text { Estimated Volume of } \\
\text { Biodiesel Purified (mL) }\end{array}$ & $\begin{array}{c}\text { Soap Removal Capacity (mL } \\
\text { Biodiesel /g Adsorbent) }\end{array}$ \\
\hline \hline BD & 66 & $>1.01$ & Nearly 1306 & 920 & 51.1 \\
\hline SD & 66 & $<0.41$ & Nearly 1552 & 440 & 24.4 \\
\hline WS & 66 & $<0.42$ & Nearly 1178 & 170 & 9.4 \\
\hline
\end{tabular}

consist of $40-50 \%$ cellulose, $20-30 \%$ hemicellulose and $15-30 \%$ lignin $[39,40]$. An FT-IR spectrum of sawdust was presented in Figure 7 (FTIR of wood shavings is similar to sawdust, not shown in this paper). There was a broad absorbance at around $3400 \mathrm{~cm}^{-1}$, which corresponded to stretching bands of $-\mathrm{OH}$ (existing hydrogen bond) $(17,18)$. The region between 1650$1750 \mathrm{~cm}^{-1}$ were attributed to the carbonyl and carboxyl $\mathrm{C}=\mathrm{O}$ stretching [41]. The peak at $1440 \mathrm{~cm}^{-1}$ was responsible for the carboxylic functional group [42]. The relatively high peak at $1055 \mathrm{~cm}^{-1}$ corresponded to the C-O stretching [41]. Hence, sawdust and wood shavings were able to provide hydrogen ions for exchanging with cations $\mathrm{K}^{+}$in soap, therefore generated a very limited amount of FFA. This explained a slight increase in acid number of biodiesel purified using sawdust or wood shavings.

For BD Zorb, ion exchange played an important role in the dry washing process due to the presence of resins in wood chips. This can be seen from a much higher soap removal capacity (two times higher than sawdust) and dramatically increased acid number in the purified biodiesel.

\section{CONCLUSIONS}

Purifying crude biodiesel using dry washing media is an attractive and sustainable option. This study demonstrated that three fiber-based biosorbents (BD Zorb, SD and WS) were able to effectively remove soap from crude camelina biodiesel. The soap removal capacity was $9.4 \mathrm{~mL} / \mathrm{g}, 24.4 \mathrm{~mL} / \mathrm{g}$ and $51.1 \mathrm{~mL} / \mathrm{g}$ for WS, SD and commercially available adsorbent, BDZorb respectively from an initial soap content of 9007 ppm. BD-Zorb exhibited the highest soap removal capacity, however, the acid number of BD-Zorb purified camelina biodiesel ( $>1 \mathrm{mg} \mathrm{KOH} / \mathrm{g}$ ) was much higher than the limit of $0.5 \mathrm{mg} \mathrm{KOH} / \mathrm{g}$ specified in the ASTM D6751 standard due to the existence of a small amount of resin. The mechanism of soap removal using sawdust and wood shavings was physical filtration and adsorption, while for BD-Zorb, ion exchange mechanism was involved in the soap removal. The water content of camelina biodiesel purified using the three biosorbents were all greater than the limit of 500 ppm stated in biodiesel quality references. These results indicate that additional steps are necessary to decrease the water content and acid number of biodiesel purified by fiber-based dry washing media.

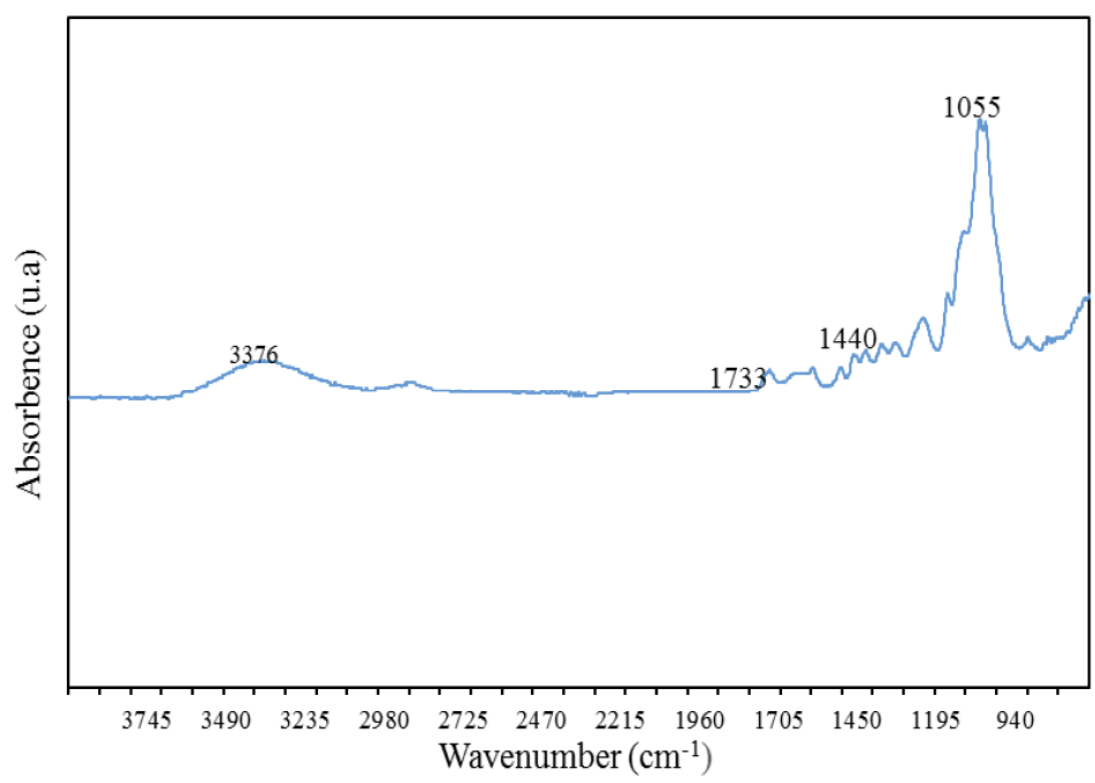

Figure 7: FT-IR spectrum of sawdust. 
Sawdust and wood shavings do have potential as economical adsorbents for the purification of crude biodiesel, however, compared to commercially available adsorbents, a lower purification capacity implies more frequent replacements of adsorbents packed in purification towers, which might lead to an increase in labor costs. A thorough evaluation of the economic viability of using wood wastes is essential in the future research.

\section{ACKNOWLEDGEMENTS}

The authors acknowledge the financial support from NSERC Discovery (RGPIN 04211), Growing Forward (RA14-0030) from Department of Agriculture, Nova Scotia, Bo Fang for carrying out preliminary experiments, and Chris Nelson for providing wood sawdust and wood shavings.

\section{REFERENCES}

[1] Bankovic-llic IB, Stamenkovic OS, Veljkovic VB. Biodiesel production from non-edible plant oils. Renew Sustain Energy Rev 2012; 16: 3621-47. https://doi.org/10.1016/..rser.2012.03.002

[2] Omidvarborna H, Kumar A, Kim D-S. Characterization of particulate matter emitted from transit buses fueled with B20 in idle modes. J Environ Chem Eng 2014; 2: 2335-42. https://doi.org/10.1016/j.jece.2014.09.020

[3] Leung DYC, Wu X, Leung MKH. A review on biodiesel production using catalyzed transesterification. Appl Energy 2010; 87: 1083-95.

https://doi.org/10.1016/j.apenergy.2009.10.006

[4] Škrbić B, Predojević Z, Đurišić-Mladenović N. Esterification of sludge palm oil as a pretreatment step for biodiesel production. Waste Manag Res 2015; 0734242X15587546.

[5] Sani YM, Daud WMAW, Abdul Aziz AR. Solid acid-catalyzed biodiesel production from microalgal oil-The dual advantage. J Environ Chem Eng 2013; 1: 113-21. https://doi.org/10.1016/j.jece.2013.04.006

[6] Stojković IJ, Stamenković OS, Povrenović DS, Veljković VB. Purification technologies for crude biodiesel obtained by alkali-catalyzed transesterification. Renew Sustain Energy Rev 2014; 32: 1-15. https://doi.org/10.1016/..rser.2014.01.005

[7] Atadashi IM, Aroua MK, Aziz AA. Biodiesel separation and purification: A review. Renew Energy 2011; 36: 437-43. https://doi.org/10.1016/j.renene.2010.07.019

[8] Atabani AE, Silitonga AS, Badruddin IA, Mahlia TMI, Masjuki $\mathrm{HH}$, Mekhilef S. A comprehensive review on biodiesel as an alternative energy resource and its characteristics. Renew Sustain Energy Rev 2012; 16: 2070-93. https://doi.org/10.1016/j.rser.2012.01.003

[9] Wan-Ghazali WNM, Mamat R, Masjuki HH, Najafi G. Effects of biodiesel from different feedstocks on engine performance and emissions: A review. Renew Sustain Energy Rev 2015; 51: 585-602.

https://doi.org/10.1016/j.rser.2015.06.031

[10] Berrios M, Skelton RL. Comparison of purification methods for biodiesel. Chem Eng J 2008; 144: 459-65. https://doi.org/10.1016/j.cej.2008.07.019
Atadashi IM, Aroua MK, Aziz ARA, Sulaiman NMN. Refining technologies for the purification of crude biodiesel. Appl Energy 2011; 88: 4239-51. https://doi.org/10.1016/j.apenergy.2011.05.029

[12] Atadashi IM. Purification of crude biodiesel using dry washing and membrane technologies. Alex Eng J 2015; 54: 1265-72.

https://doi.org/10.1016/j.aej.2015.08.005

[13] Wall JA, Van Gerpen JH, Thompson JC. Soap and glycerin removal from biodiesel using waterless processes. Trans ASABE 2011; 54: 535-41.

https://doi.org/10.13031/2013.36456

[14] Faccini CS, Cunha ME da, Moraes MSA, et al. Dry washing in biodiesel purification: a comparative study of adsorbents. $J$ Braz Chem Soc 2011; 22: 558-63. https://doi.org/10.1590/S0103-50532011000300021

[15] Fadhil AB, Dheyab MM, Abdul-Qader A-QY. Purification of biodiesel using activated carbons produced from spent tea waste. J Assoc Arab Univ Basic Appl Sci 2012; 11: 45-9. https://doi.org/10.1016/j.jaubas.2011.12.001

[16] Leinonen $\mathrm{H}$, Lehto $\mathrm{J}$. Purification of metal finishing waste waters with zeolites and activated carbons. Waste Manag Res 2001; 19: 45-57. https://doi.org/10.1177/0734242X0101900106

[17] Squissato AL, Fernandes DM, Sousa RMF, et al. Eucalyptus pulp as an adsorbent for biodiesel purification. Cellulose 2015; 22: 1263-74 https://doi.org/10.1007/s10570-015-0557-7

[18] Manique MC, Faccini CS, Onorevoli B, Benvenutti EV, Caramão EB. Rice husk ash as an adsorbent for purifying biodiesel from waste frying oil. Fuel 2012; 92: 56-61. https://doi.org/10.1016/j.fuel.2011.07.024

[19] Gomes MCS, Arroyo PA, Pereira NC. Influence of acidified water addition on the biodiesel and glycerol separation through membrane technology. J Membr Sci 2013; 431: 2836.

\section{https://doi.org/10.1016/j.memsci.2012.12.036}

[20] Hokkanen S, Bhatnagar A, Sillanpää M. A review on modification methods to cellulose-based adsorbents to improve adsorption capacity. Water Res 2016; 91: 156-73. https://doi.org/10.1016/j.watres.2016.01.008

[21] Tapia-Orozco N, Ibarra-Cabrera R, Tecante A, Gimeno M, Parra R, Garcia-Arrazola R. Removal strategies for endocrine disrupting chemicals using cellulose-based materials as adsorbents: A review. J Environ Chem Eng 2016; 4: 3122-42. https://doi.org/10.1016/j.jece.2016.06.025

[22] Heinze T, Liebert T. Unconventional methods in cellulose functionalization. Prog Polym Sci 2001; 26: 1689-762. https://doi.org/10.1016/S0079-6700(01)00022-3

[23] Hokkanen S, Bhatnagar A, Repo E, Lou S, Sillanpää M Calcium hydroxyapatite microfibrillated cellulose composite as a potential adsorbent for the removal of $\mathrm{Cr}(\mathrm{VI})$ from aqueous solution. Chem Eng J 2016; 283: 445-52. https://doi.org/10.1016/j.cej.2015.07.035

[24] Hokkanen S, Repo E, Suopajärvi T, Liimatainen H, Niinimaa $\mathrm{J}$, Sillanpää $\mathrm{M}$. Adsorption of $\mathrm{Ni}(\mathrm{II}), \mathrm{Cu}(\mathrm{II})$ and $\mathrm{Cd}(\mathrm{II})$ from aqueous solutions by amino modified nanostructured microfibrillated cellulose. Cellulose 2014; 21: 1471-87. https://doi.org/10.1007/s10570-014-0240-4

[25] Hokkanen S, Repo E, Bhatnagar A, Tang WZ, Sillanpää M. Adsorption of hydrogen sulphide from aqueous solutions using modified nano/micro fibrillated cellulose. Environ Technol 2014; 35: 2334-46. https://doi.org/10.1080/09593330.2014.903300

[26] Gui MM, Lee KT, Bhatia S. Feasibility of edible oil vs. nonedible oil vs. waste edible oil as biodiesel feedstock. Energy 2008; 33: 1646-53

https://doi.org/10.1016/j.energy.2008.06.002 
[27] Demirbas A. Competitive liquid biofuels from biomass. Appl Energy 2011; 88: 17-28.

https://doi.org/10.1016/j.apenergy.2010.07.016

[28] Krohn BJ, Fripp M. A life cycle assessment of biodiesel derived from the "niche filling" energy crop camelina in the USA. Appl Energy 2012; 92: 92-8.

https://doi.org/10.1016/j.apenergy.2011.10.025

[29] Urbaniak SD, Caldwell CD, Zheljazkov VD, Lada R, Luan L. effect of cultivar and applied nitrogen on the performance of Camelina sativa L. in the Maritime Provinces of Canada. Can J Plant Sci 2008; 88: 111-9. https://doi.org/10.4141/CJPS07115

[30] Gugel RK, Falk KC. Agronomic and seed quality evaluation of Camelina sativa in western Canada. Can J Plant Sci 2006; 86: 1047-58 https://doi.org/10.4141/P04-081

[31] Jiang $Y$, Caldwell CD, Falk KC. Camelina seed quality in response to applied nitrogen, genotype and environment. Can J Plant Sci 2014; 94: 971-80. https://doi.org/10.4141/cjps2013-396

[32] Kirkhus B, Lundon AR, Haugen J-E, Vogt G, Borge GIA, Henriksen BIF. Effects of Environmental Factors on Edible Oil Quality of Organically Grown Camelina sativa. J Agric Food Chem 2013; 61: 3179-85. https://doi.org/10.1021/jf304532u

[33] Iskandarov U, Kim HJ, Cahoon EB. Camelina: An Emerging Oilseed Platform for Advanced Biofuels and Bio-Based Materials. In: McCann MC, Buckeridge MS, Carpita NC, editors. Plants and BioEnergy. Springer New York 2014; pp. 131-40. https://doi.org/10.1007/978-1-4614-9329-7 8

[34] Veljković VB, Avramović JM, Stamenković OS. Biodiesel production by ultrasound-assisted transesterification: State of the art and the perspectives. Renew Sustain Energy Rev 2012; 16: 1193-209.

https://doi.org/10.1016/j.rser.2011.11.022
[35] Yang J, Corscadden K, He QS, Caldwell C. The optimization of alkali-catalyzed biodiesel production from Camelina sativa oil using a response surface methodology. J Bioprocess Biotech 2015; 5. Available from: http://www.omicsonline.org/ open-access/the-optimization-of-alkalicatalyzed-biodieselproduction-from-camelina-sativa-oil-using-a-responsesurface-methodology-2155-9821-1000235. php?aid=55251

[36] Yang J, Astatkie T, He QS. A comparative study on the effect of unsaturation degree of camelina and canola oils on the optimization of bio-diesel production. Energy Rep 2016; 2: 211-7. https://doi.org/10.1016/j.egyr.2016.08.003

[37] Gerpen JV. Biodiesel processing and production. Fuel Process Technol 2005; 86: 1097-107. https://doi.org/10.1016/j.fuproc.2004.11.005

[38] Yang J, Caldwell C, Corscadden K, He QS, Li J. An evaluation of biodiesel production from Camelina sativa grown in Nova Scotia. Ind Crops Prod 2016; 81: 162-8. https://doi.org/10.1016/j.indcrop.2015.11.073

[39] Khalil HPSA, Alwani MS, Omar AKM. Chemical compostion, anatomy, lignin distribution, and cell wall structure of Malaysian plant waste fibers. BioResources 2007; 1: 220-32.

[40] Li X, Tabil LG, Panigrahi S. Chemical Treatments of Natural Fiber for Use in Natural Fiber-Reinforced Composites: A Review. J Polym Environ 2007; 15: 25-33. https://doi.org/10.1007/s10924-006-0042-3

[41] Shin S, Jang J, Yoon S-H, Mochida I. A study on the effect of heat treatment on functional groups of pitch based activated carbon fiber using FTIR. Carbon 1997; 35: 1739-43. https://doi.org/10.1016/S0008-6223(97)00132-2

[42] Terzyk AP. The influence of activated carbon surface chemical composition on the adsorption of acetaminophen (paracetamol) in vitro: Part II. TG, FTIR, and XPS analysis of carbons and the temperature dependence of adsorption kinetics at the neutral $\mathrm{pH}$. Colloids Surf Physicochem Eng Asp 2001; 177: 23-45. https://doi.org/10.1016/S0927-7757(00)00594-X

Received on 01-11-2016

DOI: http://dx.doi.org/10.6000/1929-6002.2016.05.04.2

(c) 2016 Yang et al.; Licensee Lifescience Global.

This is an open access article licensed under the terms of the Creative Commons Attribution Non-Commercial License (http://creativecommons.org/licenses/by-nc/3.0/) which permits unrestricted, non-commercial use, distribution and reproduction in any medium, provided the work is properly cited. 